Rufus H. Gouws*

\title{
Equivalent relations, context and cotext in bilingual dictionaries
}

\begin{abstract}
Users of bilingual dictionaries often have problems to choose the correct translation equivalent for a given occurrence of the source language form. This could be due to a lack of entries indicating the relevant context and cotext of the translation equivalents. This paper deals with different types of equivalent relations in bilingual dictionaries and the varying need for entries to support the translation equivalents. It is argued that where a relation of semantic divergence prevails the inclusion of context and cotext entries are of extreme importance. The function of a dictionary should determine the nature and extent of the supporting entries. Lexicographers should be well aware of the additional need for context and cotext entries in the treatment of synsemantic words. Consequently they have to negotiate the problems resulting from under addressing, over addressing and zero addressing. It is suggested that procedures of addressing equivalence can help to ensure equivalent discrimination.
\end{abstract}

\section{Equivalent relations in bilingual dictionaries}

The translation equivalent paradigm, i.e. all the translation equivalents entered in the comment on semantics of an article in a translation dictionary, can be regarded as the most salient data category in such a dictionary. Contrary to what dictionary users often think, a specific translation equivalent may not arbitrarily be regarded as the meaning of the lemma. A translation equivalent is a target language item, which can be used to substitute the source language item in a specific occurrence, depending on specific contextual and cotextual restrictions.

The relation between source and target language items, i.e. the relation between the lemma and the items included in the translation equivalent

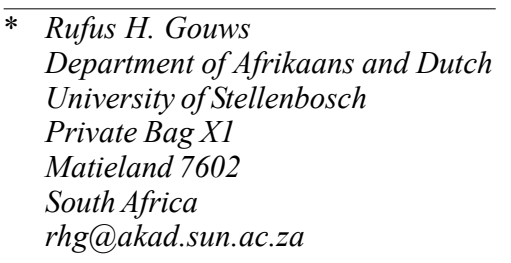

Hermes, Journal of Linguistics no. 28-2002 
196

paradigm, is known as an equivalent relation and different types of equivalent relations can be identified in translation dictionaries. These differences are the result of varying degrees of equivalence that hold between source and target language items. A distinction can be made between full equivalence, partial equivalence and zero equivalence. This distinction motivates the existence of the following types of equivalent relations: congruence (full equivalence), divergence (partial equivalence) and surrogate equivalence (zero equivalence).

\subsection{Congruence}

An equivalent relation of congruence is characterised by a one-to-one relation on lexical, pragmatic and semantic level. Both source and target language forms have exactly the same meaning, cf. the following example from Groot Woordeboek/Major Dictionary:

e'delwyn, noble wine.

Congruence implies that the translation equivalent can substitute the lemma in all its uses. For the lexicographer this type of equivalent relation holds few problems.

An equivalent relation of congruence should have an influence on the treatment offered in the comment on semantics. Tradition demands an equal treatment of all lemma types and consequently the endeavour to ensure a homogeneous article structure throughout the dictionary. However, recent research in metalexicography, cf. e.g. Bergenholtz, Tarp \& Wiegand (1999), makes provision for different types of article structures in one dictionary, e.g. the use of both single and synopsis articles. The existence of a relation of congruence implies that the comment on semantics can contain far less items aimed at contextualising and cotextualising the lexical item. Although the lexicographer may never rely on the intuition of the target user to ensure a successful dictionary consultation procedure, the lexicographer has to abstain from data redundancy and may therefore utilise a system where the absence of supporting or complementing items imply the lack of a need for an additional data presentation. This convention has to be explained in the text containing the users' guidelines so that the user can correctly interpret the absence of certain data categories in an article.

Traditionally dictionaries have been dominated by a lemmatic bias. The lemma has rightly been the primary treatment unit in translation 
dictionaries but this lemmatic bias has resulted in a totally inadequate use of non-lemmatic addressing procedures, e.g. to employ the translation equivalents functionally as secondary treatment units on a regular basis. A lexicographic approach characterised by the utilisation of non-lemmatic addressing procedures can promote translation equivalents to secondary treatment units which function e.g. as address entries of items entered for contextual and cotextual guidance. However, eschewing a lemmatic bias in favour of an approach which makes provision for a thorough implementation of non-lemmatic addressing procedures does not imply that all translation equivalents necessarily have to function as addresses of items giving contextual and cotextual guidance.

In the dictionary conceptualisation of any lexicographic product, the data distribution structure should make provision for a diversified data distribution in different articles. This data distribution has to be motivated on functional grounds and not on an attempt to provide an equal data presentation in all the articles. It is, however, of extreme importance that the implications of the data distribution structure have to be explicated in the text containing the users' guidelines.

\subsection{Divergence}

The most typical equivalent relation in translation dictionaries is one of divergence. Divergence is characterised by a one to more than one relation between source and target language forms. For a given lemma the translation equivalent paradigm will contain more than one translation equivalent. In an article displaying an equivalent relation of divergence different subtypes can be distinguished, i.e. lexical divergence, semantic divergence and polydivergence.

Lexical divergence prevails where a monosemous lexical item, functioning as lemma sign, has more than one translation equivalent. These equivalents are synonyms (usually partial synonyms) in the target language. The system used in many dictionaries is to utilise a comma as non-typographical structural marker to separate these equivalents, e.g. in Groot Woordeboek/Major Dictionary the Afrikaans lemma eerskomend has two translation equivalents, i.e. next and following.

eers'komend, (-e), next, following. 
On a semantic level there is a one to one relation between source and target language but on a lexical level there is a one to more than one relation, i.e. a relation of divergence. Where lexical divergence prevails the lexicographer has to ascertain whether the translation equivalents are full or partial synonyms. If there is a relation of complete synonymy, which is very seldom the case, the lexicographic treatment can be of a similar nature as in the case of congruence. A lack of cotext and context items will indicate that the lemma and all the equivalents share the same semantic value. More often than not an equivalent relation of lexical divergence displays equivalents which are partial synonyms. The user should not only be made aware of the fact that these partial synonyms can substitute the source language form but they should also be cautioned that the target language forms cannot substitute one another in all environments. Consequently the lexicographer should enter some kind of either contextual or cotextual guidance to indicate the typical environment where the common semantic value of the translation equivalents is activated. In the above-mentioned example a cotext entry like the following could suffice:

I'll discuss this topic at the next/following meeting.

The lexicographer may also consider using a structural marker to indicate to the user that the translation equivalents are only partial synonyms. Be it as it may, lexical divergence does not demand a sophisticated system to ensure an optimal retrieval of information but it does require a consistent application of a well-devised model.

Semantic divergence prevails where the lemma sign represents a polysemous lexical item. Polysemy is a language specific phenomenon and the chances are minimal that a single target language item will have the same semantic load as the polysemous source language item. To solve this problem the comment on semantics contains a subcomment on semantics for each one of the polysemous senses and a translation equivalent has to be entered for each polysemous sense of the source language form. Dictionaries use different methods to mark the occurrence of semantic divergence, e.g. by numbering each subcomment on semantics or by entering a semicolon as structural marker to separate the translation equivalents representing different polysemous senses of the lemma, cf. the following example from Groot Woordeboek/Major Dictionary 
where the Afrikaans lemma pasella has two translation equivalents to represent the different senses of the source language item:

pasel'la, (-s), gift; cheap sweets.

No lexicographer may assume that the users of the dictionary will intuitively know which translation equivalent to choose for a given situation. Consequently the lexicographer is compelled to utilise additional strategies to ensure an optimal retrieval of information. These strategies include procedures of contextualisation and cotextualisation.

It happens very often that both lexical and semantic divergence prevail in the translation equivalent paradigm in a given article, cf. the treatment of the lemma sign lekker ${ }^{3}$ in Groot Woordeboek/Major Dictionary

lek'ker'3, ... (b) dainty, nice, sweet, palatable, delectable, savoury, delicate, delicious; pleasant; cosy; tipsy; luscious, exquisite; cushy; merry;

In this article the translation equivalents dainty, nice, sweet, palatable, delectable, savoury, delicate, delicious and luscious, exquisite are target language synonym paradigms and they constitute the occurrence of lexical divergence, as indicated by the commas separating the members of these paradigms. These two groups of translation equivalents belong to separate subcomments on semantics and function, along with the five other subcomments on semantics occupied by the translation equivalents pleasant; cosy; tipsy; cushy; merry respectively in an equivalent relation of semantic divergence with the source language item. The co-existence of lexical and semantic divergence in one article constitutes an equivalent relation of polydivergence and demands a well-planned and consistently applied system of contextual and cotextual guidance.

\subsection{Surrogate equivalence}

The existence of lexical gaps in any given language is not uncommon. What would be uncommon for a lexicographer, however, would be to enter no translation equivalent at all for a particular source language form. Lexicographers are often confronted with the lack of a target language lexical item which can be co-ordinated semantically with a given source language form. Due to the fact that the database of the dictionary determines the inclusion of a specific lexical item as lemma sign in a dictionary, the lexicographer is compelled to treat that item by entering a 


\section{0}

target language item in order to establish some kind of an equivalent relation. Where the lexicographer is confronted with a lexical gap in the target language a surrogate equivalent is often created and entered in co-ordination with the lemma sign. Surrogate equivalents belong to different categories and their choice is determined by the nature of the lexical gap, cf. Zgusta (1987), Gouws (1989).

In his discussion of lexical gaps Dagut (1981:64) makes a distinction between lexical gaps which are motivated on linguistic grounds and those motivated on extra-linguistic grounds. This distinction leads to the existence of linguistic and referential gaps respectively. When a lexicographer is compiling a translation dictionary a linguistic gap prevails when a given referent is known to the speakers of both languages, a lexical item exists in one of the languages but in the other language the meaning has not been lexicalised. As an example: in South Africa young or baby dogs are well known to speakers of both English and Afrikaans. English has a word to refer to this creature, i.e. the word puppy. In Afrikaans, however, the meaning "young or baby dog" has not been lexicalised. A referential gap prevails where the speakers of the one of the languages treated in a translation dictionary are familiar with a specific referent and their language has a word to refer to the subject. The speakers of the other language are not familiar with the referent and consequently their language does not have a word to refer to the subject.

Lexical gaps in the target language of a translation dictionary may never result in the lexicographer refraining from an attempt to fill the subcomment on semantics with a target language entry that conveys the meaning of the source language item to the dictionary users. Language dynamics has its own remedy for lexical gaps, i.e. the use of loan words. Ever so often, especially where language contact takes place, the lexical gap is filled with a loan word functioning as surrogate equivalent. Lexicographers do not initiate these loans but where the loan words do exist in a language the lexicographer has to treat them as part of the lexicon of the given language. Their existence does not confront the lexicographer with any serious problems. However, where a loan word is not all that well established in the target language of a translation dictionary, the lexicographer often complements this translation equivalent with a brief paraphrase of meaning, cf. the treatment of the words biltong and bobotie in Groot Woordeboek/Major Dictionary and the treatment of smorgasbord in New Words/Nuwe woorde 
bil'tong, (-e), biltong (dried meat), jerky, jerked venison (beef) (U.S.); ...

bobo'tie, curried mincemeat, bobotie

smor·gas·bord $n .,(<S w$.$) , (Skand. kookk.: oop toebroodjies)$ smorgasbord, oopbroodjies; (fig.) potpourri, allegaartjie, mengelmoes; mengsel, verskeidenheid.

In the last example smorgasbord is given as a loan word in Afrikaans but this equivalent is preceded by a brief description of meaning.

A typical treatment accommodated in the subcomment on semantics where borrowing has not occurred is the use of an entry giving a paraphrase of meaning of the source language form. This explanation functions as a surrogate equivalent. The Greater Dictionary of Xhosa, a typological hybrid with a descriptive function in Xhosa as well as a translation function rendering translation equivalents in English and Afrikaans, has the Xhosa lemma ukú xhàmà. As far as the co-ordination with this lexical item is concerned both Afrikaans and English have lexical gaps and indeed referential gaps. The surrogate equivalent in English entered in the comment on semantics is:

"succeed in gaining (a girl's hand in marriage) by outbidding other competitors with the number of cattle as bride price"

This paraphrase of meaning is complemented by a cotext entry:

Sizakele gained the hand of Zweledinga's daughter by offering the largest number of cattle as bride price.

The source language version of the example sentence also functions to illustrate the form in which the lemma occurs in a given cotextual environment. In the comment on semantics the source language version is entered as

intombi kaZweledinga ixhanywe nguSizakele ${ }^{1}$

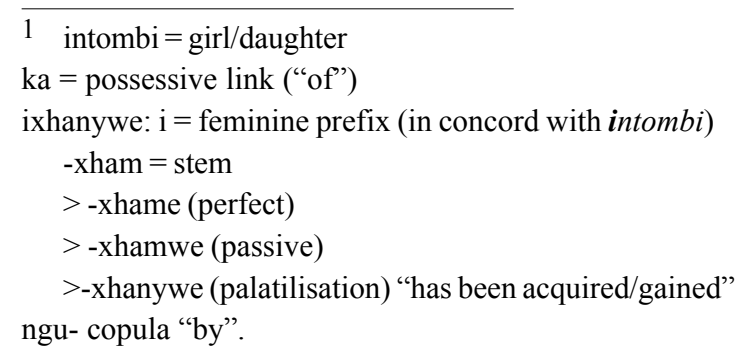




\section{2}

This example also illustrates that cotext entries function to indicate the proper grammatical use of the word they are addressed at.

The nature of the lexical gap will determine the extent of the explanation. Where a linguistic gap prevails the lexicographer knows that the users are most probably familiar with the referent. Consequently only a brief paraphrase of meaning will suffice. However, where a referential gap exists the description of meaning has to be more comprehensive in order to ensure an unambiguous interpretation of the source language item by the speakers of the target language. The nature and extent of contextual and cotextual entries will also be co-determined by the nature of both the lexical gap and the surrogate equivalent.

\section{A successful retrieval of information in bilingual dictionaries}

A user-driven lexicographic approach compels lexicographers to compile dictionaries in such a way that the intended target user achieves an optimal retrieval of information with every dictionary consultation procedure. Lexicographers apply, among others, two methods to assist their users in achieving a more successful retrieval of information from the comment on semantics of bilingual dictionaries. These methods are the use of illustrative examples to provide cotextual information along with glosses and labels to provide cotextual information and the use of synopsis articles to allow a stronger encyclopaedic approach in the treatment of culturally bound lexical items. Especially where a relation of surrogate equivalence exists, synopsis articles assist the user with a co-ordination between source and target language.

\subsection{The use of cotext and context items}

In his discussion of strategies in equivalent discrimination Gouws (2000) stresses the need for the use of procedures of non-lemmatic addressing, e.g. by entering context and cotext items, to comment on translation equivalents and to take cognisance of semiotax.

Once again the need but also the reference skills of the target users of each dictionary should play an important, an all-decisive role, in determining the extent of the use of illustrative examples. Lexicographers should also be aware of different types of illustrative examples which can be used to 
indicate the relevant cotext for a given translation equivalent, $\mathrm{cf}$. Bergenholtz \& Tarp (1995).

\subsubsection{Addressing equivalence}

The comment on semantics displays a relation of addressing equivalence if there is a one to one relation between context and cotext entries on the one hand and the members of the translation equivalent paradigm on the other hand. Addressing equivalence is no prerequisite for a successful lexicographic treatment but it can assist the user to make the correct choice of equivalents, especially in an article characterised by an equivalent relation of polydivergence.

Under addressing, in the comment/subcomment on semantics of the articles of a translation dictionary, prevails where no one to one relation between the context/cotext entries and the members of the translation equivalent paradigm exists because each translation equivalent does not function as address of a cotext or context entry. Some translation equivalents are left stranded without any supporting entries to indicate their contextual or cotextual occurrence, cf. the excerpts from Groot Woordeboek/Major Dictionary:

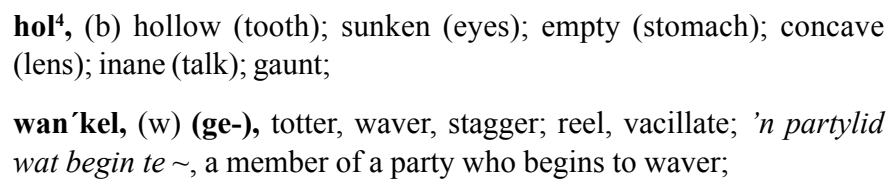

In the article of the lemma sign $\mathrm{hol}^{4}$ a context item is entered for all the translation equivalents except gaunt and in the article of the lemma sign wankel only the translation equivalent waver gets a cotext item. Some articles in this dictionary displays under addressing whilst other articles exhibit relation of addressing equivalence. No explanation is given for this arbitrary treatment of target language items. To ensure proper equivalent discrimination the lexicographers of a bilingual dictionary need to utilise a well-devised system according to which these complementing entries are allocated to the translation equivalents. This system should be explained in the text dealing with the users' guidelines.

Zero addressing, in the comment/subcomment on semantics of the articles of a translation dictionary, implies that the comment on semantics does not include any examples or glosses to contextualise or cotextualise 
204

the translation equivalents, cf. the following excerpt from Groot Woordeboek/Major Dictionary:

min'ag, (ge-), hold in contempt, despise, disdain, slight, undervalue, disesteem, contemn, disregard; misesteem;

This absence of glosses and examples is not explained anywhere in the dictionary and the user finds no guidance regarding the typical occurrence of a given target language form.

Over addressing, in the comment/subcomment on semantics of the articles of a translation dictionary, occurs when the comment on semantics includes one or more cotext entries, which do not have a member of the translation equivalent paradigm as address. Such an example introduces a new translation equivalent. The following excerpt from Groot Woordeboek/Major Dictionary illustrates this problem:

haal, (s) (hale), stroke, lash, dash; wale, weal; draw, puff (pipe); met lang hale AANKOM, approach with long strides; met een $\sim$ van die $P E N$, with one stroke of the pen; (w) (ge-), fetch, reach, catch; dash; recover; attain; realise (price); hy sal nie die DORP nie, he will not reach the town (alive); waar moet ek die GELD vandaan $\sim$ ?, where am I to get the money?; jy moet $\sim$ so wat jy KAN, you must race for all you're worth; ek KOM jou $\sim$, I am coming to fetch you; $\sim$ om daar te $K O M$, race to get there; $L A A T \sim$, send for; die sieke sal MÔRE nie $\sim$ nie, the patient will not live through the night; NIE by iem. $\sim$ nie, not to be a patch on someone; die TREIN $\sim$, catch the train; WAAR $\sim$ jy dit vandaan?, where do you get that from?; WEER gaan $\sim$, start afresh; -baar, (..bare), attainable, reachable.

The cotext entry approach with long strides introduces stride as a translation equivalent of haal, the word represented by the lemma sign, albeit that the translation equivalent paradigm makes no provision for stride as an equivalent. The word offered as equivalent of the word representing the lemma in the example has no address in the translation equivalent paradigm. A treatment like this confronts the user with definite problems and especially where the users of a dictionary have a limited knowledge of the target language or where they have limited dictionary using skills, the lack of addressing equivalence can lead to serious communication problems.

Once again it has to be stressed that addressing equivalence is not seen as the norm or even the desired situation in every comment on semantics. The consistent application of addressing equivalence in all 
articles will lead to an inflation of cotext and context entries and will decrease the functionality of this data type. However, these entries can play a very important role and the lexicographer should therefore know when and where to use them. The user must also be familiar with both their use and non-use. Context and cotext entries may not be used at random. The function(s) of a dictionary should determine the need for these entries supporting the translation equivalents and the function(s) as well as their implications should be explicated in a front matter text. One of the core features of a lexicographic process is the fact that it can be regulated, cf. Wiegand (1998:38). This brings predictability into play. The user must be able to predict the implications of either the use or the lack of context and cotext entries. Lexicographers have to employ a system and have to use these entries according to the criteria governing the system.

In the article of the lemma haal the user is at a total loss when having to choose a suitable translation equivalent. This applies to both the noun and the verb haal. The noun haal has the translation equivalents stroke, lash, dash; wale, weal; draw, and puff. Only the last translation equivalent is complemented by a context entry (pipe) while only the first translation equivalent (stroke) is the address of a cotext entry. The other translation equivalents in this article, an article that displays a relation of polydivergence, stand in a relation of zero addressing within the comment on semantics. No indication is given with regard to the typical use of the target language synonym paradigm wale, weal. Apparently the choice of equivalents to be the address of cotext and context entries has been done in an arbitrary way. This is not good enough.

Although the inferior treatment presented in the article of the lemma sign haal can be regarded as a problem for this specific Afrikaans-English dictionary, it illustrates a much more general problem which is of immense magnitude for bilingual dictionaries, especially those with an encoding function and those compiled for non-mother tongue speakers. The users of these dictionaries need explicit guidance and even in equivalent relations of lexical divergence or congruence addressing equivalence could be of prime importance. Lexicographers have to take cognisance of the notions of addressing equivalence, zero addressing, under addressing and over addressing. When planning their dictionaries and when determining the function(s) of the dictionaries they should aim to devise a system which 
206

ensures a proper inclusion of items to complement the translation equivalents. The consistent application of this system should assist the users to make the correct choice of equivalents. The assignment of the lexicographer of a bilingual dictionary is not only to achieve semantic equivalence between source and target language but also to ensure and enhance communicative equivalence. This can only be achieved if an unambiguous discrimination of translation equivalents is possible.

\subsubsection{Semiotax}

According to Hausmann (1997:172) all words presented as lemmata in a monolingual descriptive dictionary do not necessarily have the same degree of definability. Some words can easily be defined without knowledge of any cotext whereas the definition of others need a cotext. This difference between words regards the level of semiotax. Within the field of semiotax words are divided into autosemantic and synsemantic words. Autosemantic words have a higher degree of definability than synsemantic words.

The distinction between autosemantic and synsemantic words should have definite implications for translation dictionaries, cf. Gouws (2000). All words do not have the same degree of definabilty. Neither do they have the same degree of translatability. Consequently the articles of synsemantic words should display a more comprehensive presentation of cotext and context items compared to the articles of autosemantic words. Once again the lexicographer should refrain from the tradition of a compulsory homogeneous data distribution in the articles. Along with the function(s) of the dictionary the semiotax of the items to be treated should determine the nature and the extent of the context and cotext entries.

Gouws (2000) uses the Afrikaans word darem to illustrate the typical treatment allocated to synsemantic words in translation dictionaries. The translation equivalents for this word in German and English respectively would be

immerhin, dennoch, so wie so, trotzdem

though, all the same, after all, surely; in spite of, notwithstanding; really.

For the user it would be of little help if the lexicographic treatment of darem is restricted to the mere listing of translation equivalents with zero addressing. 
The translation dictionary with Afrikaans and German as language pair Woordeboek/Wörterbuch gives the following treatment of this word:

da'rem, immerhin, dennoch, so wie so; ek sal dit - maar doen, ich werde es trotzdem tun

The single cotext entry contains none of the given translation equivalents. This entry rather introduces a new translation equivalent, i.e. trotzdem, for the lemma sign. As a result of this a combination of over and under addressing between the cotext and the translation equivalent paradigm prevails in this article.

Groot Woordeboek/Major Dictionary treats the lemma sign darem as follows:

da'rem, though, all the same, after all, surely; in spite of, notwithstanding; really; ek sal dit $\sim D O E N$, I'll do it after all; JY, $\sim$ !, ah, but you! dis $\sim$ alte LAAT, it is really too late; $\sim$ maar TOESTEM, give one's consent after all.

The user is confronted with an equivalent relation of polydivergence in an article displaying a microstructure without integration where both under and over addressing prevail in the comment on semantics. A user has to be well familiar with Afrikaans to be able to make the correct choice of translation equivalents when translating darem from Afrikaans to either German or English. More comprehensive strategies of equivalent discrimination are needed in the articles of synsemantic lemma signs and the dictionary conceptualisation plan of any new project has to make provision for a diversified use of context and cotext items. Establishing a relation of addressing equivalence could solve many problems in this regard.

\subsection{Single and synopsis articles}

In their discussion of dictionaries compiled to deal with languages for special purposes Bergenholtz, Tarp \& Wiegand (1999) make a distinction between single articles and synopsis articles. The nature of the data presentation in articles form the basis of this distinction. A synopsis article in a LSP dictionary does not only contain data relevant to the lemma sign functioning as guiding element of the article but it contains data relevant to lemma signs functioning as guiding elements of other (single) articles. While single articles present a more isolated knowledge representation the synopsis articles present a more general presentation. 
The distinction between single and synopsis articles challenges the lexicographer of a general bilingual dictionary to employ new strategies in order to ensure an optimal transfer of knowledge in the dictionary. Especially in a multilingual and multicultural environment synopsis articles, albeit under another name, could give the lexicographer of a bilingual dictionary yet another option in the planning of the data distribution structure of his dictionary.

Culturally bound words often need a more comprehensive treatment than the article of a traditional bilingual dictionary can accommodate. Even the brief paraphrase of meaning entered as a surrogate equivalent and the context and cotext entries do not always suffice to transfer the meaning of the source language item to the target language. A bilingual dictionary with synopsis articles in which the comment on semantics includes an additional search zone allocated to encyclopaedic data could benefit the lexicographic practice in no small way. Such synopsis articles could play a big role in promoting the cultural values of the languages treated in the dictionary.

\section{In closing}

Cotext and context can play an important role to ensure an optimal retrieval of information from bilingual dictionaries. Where relations of divergence or surrogate equivalence prevail these entries can help to assist the user so that dictionaries can really function as instruments of communicative empowerment. Lexicographers of bilingual dictionaries have to be familiar with the results of metalexicographic research and have to negotiate the different functions of dictionaries and the differences prevailing between words on the level of semiotax. Today lexicographers are in the fortunate position of being able to rely on the work done by metalexicographers. When planning and compiling their dictionaries they may not make the same mistakes as their predecessors. 


\section{References}

Bergenholtz, H. \& S. Tarp (eds.) (1995). Manual of Specialised Lexicography. Amsterdam: John Benjamins.

Bergenholtz, H. S. Tarp \& H.E. Wiegand. (1999). Datendistributionsstrukturen, Makround Mikrostrukturen in neueren Fachwörterbüchern. In Hoffmann, L. et al. (eds.) 1999. Fachsprachen. Languages for Special Purposes. Berlin: De Gruyter: 17621832.

Dagut, M. (1981). Semantic voids as a problem in the translation process. In Poetics Today 2/4:61-71.

Du Plessis, M. (1999). New Words Nuwe Woorde. Cape Town: Pharos.

Eksteen, L.C. et al. (eds.) (1997) ${ }^{14}$. Groot Woordeboek/Major Dictionary. Cape Town: Pharos.

Gouws, R.H. (1989). Leksikografie. Cape Town: Academica.

Gouws, R.H. (2000). Strategies in equivalent discrimination. In Mogensen, J.E. et al. (eds.) 2000. Symposium on Lexicography IX. Tübingen: Max Niemeyer: 99-111.

Hausmann, F.J. (1997). Semiotaxis und Wörterbuch. In Konerding, K-P \& A. Lehr (eds.) 1997. In Linguistische Theorie und lexikographische Praxis. Tübingen: Max Niemeyer: 171-179.

Pahl, H.W. (ed.) (1989). The Greater Dictionary of Xhosa. Alice: University of Fort Hare.

Wiegand, H.E. (1998). Wörterbuchforschung. Berlin: De Gruyter.

Zgusta, L. (1987). Translation equivalence in a bilingual dictionary. In Dictionaries 9: 147. 
